\title{
A RELEVÂNCIA DO MANUAL NA ORGANIZAÇAO E REALIZAÇAO DE VISITAS E VIAGENS TÉCNICAS
}

Fernanda Rosa dos Santos Mestre em Sistemas de Gestão (UFF), Professora EBTT do CEFET/RJ, Rio de Janeiro, RJ, Brasil fernanda.santos@cefet-rj.br

Guido Vaz Silva Doutor em Engenharia de Produção (UFRJ); Professor Adjunto da UFF, Niterói, RJ, Brasil guido_vaz@id.uff.br

Jorge Luiz Silva de Lemos Doutor em Ciências (Fiocruz), Professor Titular do CFET/RJ, Rio de Janeiro, RJ, Brasil jorge.lemos@cefet-rj.br

\section{RESUMO}

Este artigo trata da elaboração de um manual como um conjunto de normas e recomendações para a sistematização do processo de planejamento e organização das visitas e viagens técnicas no CEFET/RJ, como forma de mitigar os entraves encontrados. Analisa as impressões dos docentes das áreas técnica e propedêutica sobre a realização das visitas e viagens técnicas, desde a sua relevância enquanto estratégia de ensino, sua relação com o conteúdo programático desenvolvido à infraestrutura necessária para sua efetiva realização. Baseada na pesquisa qualitativa, este estudo desenvolve por meio de levantamento documental e bibliográfico e aplicação de entrevista semiestruturada. Ressalta a relevância das visitas e viagens técnicas no contexto acadêmico. Identifica a existência de lacunas no processo de organização, tais como a falta de padronização ou critérios previamente estabelecidos para o planejamento. O manual é condicente com a metodologia da Design Science Research. As visitas e viagens técnicas são capazes de proporcionar vivências enriquecedoras, uma aprendizagem mais efetiva em contextos mais práticos e ativos, por meio da interligação com espaços de educação não formais, com o mercado de trabalho, entre outras possibilidades cuja organização ainda que exija maior complexidade, a realização adequa-se perfeitamente a cursos de formações e níveis de ensino distintos.

Palavras-chave: Manual. Visitas e viagens técnicas. Ensinos Formal e Não Formal. Interdisciplinaridade. 


\title{
THE RELEVANCE OF A MANUAL IN THE ORGANIZATION AND CONDUCT OF TECHNICAL VISITS AND TRIPS
}

\begin{abstract}
This paper focuses on the development of a manual with a set of standards and recommendations for the systematization of technical visits and trips planning and organizing process at Cefet/RJ, as a way of mitigate barriers founded. Analyze technical and propedeutic teaching staff impressions about realizing technical visits and trips, since its relevance like educational strategy, its relation to syllabus content developed to the required infrastructure to its effective realization. Based on qualitative research, this study develops through document and bibliographic procedures and semi-structured interview appliance. Emphasize the technical visits and trips relevance on academic content. Identify the existence of gaps into the organization process, like a lack of standardization or planning principles previously established. The manual reflects the Design Science Research methodology. The technical visits and trips are able to provide enrichment experiences, more effective learning in practical and more active contexts, through the interlinking with non-formal educational spaces, with the labour market, among other possibilities which organization although demands greater complexity, its realization fits perfectly to different training and level courses.
\end{abstract}

Keywords: Manual. Tchnical visits and trips. Formal and non-formal education. Interdisciplinarity.

\section{INTRODUÇÃO}

De forma a contribuir com o mercado, o governo, por meio de políticas públicas e da educação, vem empreendendo esforços em todas as instâncias. A formação do guia de turismo no Brasil teve início ainda na década de 60, antecedendo a do bacharel em turismo. Era realizada por meio de cursos livres, ganhou força com o reconhecimento em 1986 e com a regulamentação da profissão em 1993, passando a exigir uma formação mais robusta quando se transforma em profissão de nível médio-técnico (MONTES, 2013).

A formação pautada em habilidades e competências ressaltou a necessidade de maior intercâmbio entre a teoria e a prática, valorizando a visita técnica. Entendida como metodologia de aprendizagem, a visita técnica tem integrado a maioria dos currículos na condição de atividade complementar e até mesmo opcional. 
No contexto da formação do guia de turismo a visita técnica ganha outra proporção, tornando-se imprescindível. Essa atividade permite ao discente, além de interligar teoria e prática, experimentar a função a ser desempenhada e suas nuances, pois cada visita está condicionada a fatores externos e, ainda que devidamente planejadas, podem sofrer alterações entre outras intervenções, desde humanas a climáticas, o que faz de cada atividade única (VELOSO, 2003).

A visita técnica permite a experimentação e a representação das atividades profissionais a serem desempenhadas pelo guia de turismo, tais como: a realização de transfers - transporte de passageiros dos terminais de transportes para a hospedagem e vice-versa; city-tours e sightseeings - visitas aos atrativos turísticos, excursões, entre outros serviços, os quais somente com a prática, o tempo e a experiência trar-lhe-ão a autonomia necessária para o exercício profissional com a devida confiança e a qualidade esperada pelos clientes: contratantes e passageiros.

A qualidade requerida para a prestação de serviços no turismo, precisa ter seu início na qualidade e excelência do serviço de educação para a formação dos seus profissionais. Com base nisso este estudo tem por objetivo gerar um artefato que permita sistematizar os trâmites e as etapas para o planejamento, a organização e a realização das visitas técnicas do curso técnico de guia de turismo.

Em consonância com os inúmeros avanços que possibilitaram um mundo mais globalizado, o setor de serviços, em especial os turísticos, têm requerido mudanças constantes para que possam acompanhar as tendências do mercado.

Essas mudanças têm influência direta na educação já que o mercado globalizado se torna mais competitivo e exigente quanto à qualidade, adotando muitas vezes padrões internacionais, o que passa a requerer profissionais melhor ou altamente qualificados.

A qualidade educacional pode ser alcançada, entre outras formas, por meio de constantes revisões e atualizações pedagógicas e metodológicas e de um ensino profissionalizante polivalente devidamente articulado com o mercado de trabalho e que acima de tudo forma um cidadão ativo, crítico, capaz de intervir positivamente no contexto social que o circunda.

Em atenção à Política de Educação Profissional do Ministério da Educação (MEC) que objetiva promover a interação entre a escola e o mundo do trabalho, por meio da capacitação de jovens e adultos aliando competências e habilidades para o exercício de atividades produtivas, faz-se necessário que o ensino técnico profissionalizante considere a formação de um cidadão responsável e comprometido com o bem-estar 
coletivo e precisa estar integrado, a fim de evitar o distanciamento recorrente entre o ensino propedêutico e a educação profissional.

A integralização dos saberes formais e informais e dos conhecimentos teóricos e práticos encontra na realização das visitas técnicas o recurso metodológico diferencial e primordial para a formação técnica do profissional guia de turismo.

De acordo com o Instituto Federal de Educação, Ciência e Tecnologia do Estado de São Paulo (2011, p. 2)

As visitas técnicas são consideradas atividades de ato educativo escolar supervisionado, desenvolvido em ambiente externo à instituição de ensino, visando ampliar os conhecimentos relacionados ao trabalho e à preparação para o trabalho produtivo, assim como uma ferramenta para formação integral do educando como cidadão.Erro! Fonte de referência não encontrada.

Para que a visita técnica se configure em materialização das atividades e funções desempenhadas pelo profissional guia de turismo, torna-se necessária uma organização criteriosa de cada etapa e ação pertinentes à sua efetivação.

A realização das visitas técnicas encontra-se prevista e garantida como prática profissional obrigatória no Plano Pedagógico do Curso Médio Integrado ao Técnico em Guia de Turismo do Centro Federal de Educação Tecnológica Celso Suckow da Fonseca (CEFET/RJ), porém ainda sem uma sistematização oficial para a sua organização e realização, carecendo assim de maior rigor neste sentido. Ainda hoje é organizada de acordo com cada docente ou colegiado, não tendo seus trâmites padronizados.

A identificação de alguns problemas relacionados à organização e à operacionalização destas atividades práticas são os fatores norteadores desta pesquisa. Os docentes consultados e que realizam estas atividades relataram limitações do ponto de vista burocrático, de segurança, de recursos para o financiamento de algumas práticas previstas no PPC, mas ainda não legitimadas e não contempladas no planejamento financeiro.

Assim sendo, pretendeu-se utilizar este estudo para a criação de um manual como artefato, visando sistematizar todo o processo necessário em prol da melhoria da qualidade da atividade e do curso em questão.

A atividade turística integra um mercado dinâmico, com interferências constantes de ordem social a econômica e, por isso, demanda profissionais atualizados e autônomos, 
capazes de desempenhar suas funções e tomar as decisões necessárias frente aos imprevistos e crises, comuns ao dia-a-dia do profissional guia de turismo.

No curso técnico em guia de turismo as visitas e a viagens técnica com pernoite são componentes obrigatórias, conforme estabelecido no PPC, nas seguintes disciplinas: Teoria e Prática Profissional I e II, Teoria e Prática do Atrativo Cultural e Teoria e Prática do Atrativo Natural e com carga horária mínima de 200 (duzentas) horas. São aplicadas ainda em outras disciplinas a critério de cada docente.

As visitas técnicas em suas diferentes denominações: visitas de estudo, saídas de estudo ou técnica, aula de campo, entre outras são adotadas em todos os níveis de ensino da instituição, do técnico em segurança do trabalho às engenharias, porém em sua maioria, na condição de atividade complementar ou opcional.

Independentemente do contexto e da obrigatoriedade ou não, tal atividade requer todo um planejamento e organização, porque, além de envolver o conteúdo e a formação profissional dos discentes, a sua realização passa por diversos setores e instâncias da instituição. Requer preparação do ponto de vista pedagógico, locação de transporte, disponibilidade e agendamento dos espaços e destinos para recepção dos participantes, viabilidade financeira, entre outros requisitos igualmente importantes.

Neste estudo, é dado enfoque ao curso de guia de turismo, por ser este o que envolve maior complexidade na organização dessa atividade, porque a visita além de ter a função de estudo e pesquisa de um tema ou localidade, corresponde a um laboratório ou estágio, por ser o momento em que o discente colocará em prática a teoria vista em sala, desempenhando as funções que exercerá quando da sua formação como guia de turismo. Para tanto, o volume de informações e documentação é mais complexo, pois agregam ainda as viagens com hospedagem nos destinos, enquanto nos demais cursos ocorrem, em sua maioria, em visitas de meio período ou de um dia a empresas ou outros espaços de educação não formal.

Por meio de entrevista a docentes com experiência na operacionalização desse tipo de atividade na instituição foram identificadas algumas lacunas, tais como: a falta de um guia ou documento norteador das etapas necessárias para o planejamento dessas atividades, apontando suas especificidades e diferenciações, para aquelas visitas de meio período ou as de um dia e para aquelas que requerem pernoite no destino; autorizações dos responsáveis e termos de compromisso para os alunos; viabilidade financeira para custear despesas como hospedagem, alimentação, seguro e ingressos, quando não for concedida gratuidade; orientação para os trâmites dos processos de compras e 
licitação necessários a essa organização, os prazos a serem cumpridos desde a previsão orçamentária até a execução de cada atividade, até a organização para a disponibilização de acompanhante como apoio do docente organizador da atividade, por questões de precaução e segurança, pois estas saídas acontecem com turmas inteiras por vez, com média superior a 25 participantes em se tratando dos cursos técnicos de nível médio.

A necessidade de sistematização do processo de organização das visitas e viagens técnicas objetiva não apenas a melhoria da qualidade dessas atividades práticas, mas também a dos cursos, caracterizando-se, assim, como fator motivador e aspecto de maior relevância para este estudo. Ressalta-se que a existência de maior rigor não está relacionada à burocratização ou engessamento do sistema e sim à melhor organização e operacionalização para a instituição e sua clientela. É importante ressaltar que a melhoria alcançada com essas ações gerará reação em cadeia refletindo positivamente na qualidade do profissional formado pela instituição.

Neste sentido, este estudo de natureza qualitativa tem como objetivo geral sistematizar os processos que englobam a realização das visitas e viagens técnicas, por meio da criação de um manual que estabeleça normas para a sua realização.

Este estudo está delimitado ao campus Maracanã do CEFET/RJ por ser o único entre os oito campi em funcionamento a ofertar o Curso Médio Integrado ao Técnico em Guia de Turismo Regional com especialização em atrativos culturais e naturais.

O referido curso é ofertado desde 2014, em substituição Curso Técnico em Turismo e Entretenimento, que funcionou de 2002 a 2013, na instituição.

\section{DESENVOLVIMENTO}

Nas últimas décadas, o Brasil e o mundo têm passado por inúmeras transformações de ordem social, histórico-cultural, econômica, geográfica e política. 0 avanço da tecnologia, desde a Revolução Industrial à expansão dos meios de transportes e comunicação, alavancou o deslocamento e as relações interpessoais, culturais e de comércio entre os povos.

Essa integração permitiu o avanço do turismo, atividade caracterizada pelo deslocamento e pelas reações entre povos e com destinos.

Na sociedade contemporânea é indiscutível o significado do turismo como atividade e o seu desenvolvimento em larga escala propiciou o avanço de estudos e conhecimentos acadêmicos (TRIBE, 2010). 
O turismo hoje é considerado uma indústria, dada a sua dimensão econômica, a complexa gama de bens e serviços que compreende. Porém esta definição não é unânime entre os autores.

Alguns autores não o legitimam desta forma pelo fato de que por indústria entende-se "o conjunto de unidades econômicas de produção que, pela utilização de fatores produtivos (capital e trabalho), transformam os bens reais em produtos". O turismo é entendido como atividade turística e não como indústria em função da intangibilidade da prestação de serviços e das especificidades e peculiaridades do setor terciário da economia (NETO e ANDRADE, 2001).

Defendem que o turismo deve ser entendido como atividade porque o produto final da indústria é distribuído no mercado, enquanto o turismo é composto por uma diversidade de produtos, não de um singular e que a demanda por meio do sistema de distribuição e serviços é que se dirige aos produtos.

Somado a toda a complexidade que envolve o sistema turístico, há a figura do profissional guia de turismo tido como um articulador, o responsável pela concretização do projeto.

Ao guia cabe não somente conduzir pelos caminhos mais interessantes e de paisagem mais encantadora, mas toda a preocupação com a segurança de seus clientes e a certeza de que o roteiro está de acordo com a condição dos participantes. É prática desse profissional monitorar de maneira sutil a disposição do turista a fim de motivar ou acalmar, administrando seu próprio trabalho entre o lado técnico de responsabilidade como representante in loco da agência de viagens e seu cuidado com o lado humano dos clientes e suas tão diversas necessidades (CAMPOS e SERPA, 2014).

\subsection{A Instituição CEFET/RJ}

Em 1917 é fundada a Escola Normal de artes e Ofícios Wenceslau Braz dedicada a formação de professores para o ensino profissional, a única daquela época, e que em 1937 é transformada em Liceu com foco na formação de profissionais de diferentes setores e graus. Em 1942, por meio de decreto passa a chamar-se Escola Técnica Nacional e teve seu foco direcionado ao ensino industrial.

Em 1959, extinguiu os cursos do ciclo básico passando a dedicar-se exclusivamente 
aos cursos técnicos. Em 1966 teve a implantação de seu primeiro curso de graduação de curta direção em Engenharia de Operações, desenvolvido por meio de parceria com a Universidade Federal do Rio de Janeiro, para colaboração docente e expedição de diplomas. Essa expansão demandava professores com formação específica para atuar em determinadas disciplinas dos cursos técnicos e da graduação, com isso em 1971 criou o Centro de Treinamento de Professores. Em 1975, foi designada como Escola Técnica Federal da Guanabara e em 1967, mais uma modificação para Escola Técnica Federal Celso Suckow da Fonseca, mudança feita como homenagem póstuma ao seu primeiro diretor.

A designação atual teve origem por meio de uma lei promulgada em 1978, transformando-a no Centro Federal de Educação Tecnológica Celso Suckow da Fonseca, uma autarquia vinculada ao Ministério da Educação com autonomia administrativa, financeira, didática e disciplinar nas atividades de pesquisa, extensão e dos diferentes níveis de ensino em que atua, médio, técnico, graduação e pós-graduação.

A instituição possui, atualmente, oito campi no Estado do Rio de Janeiro. Dentre os campi, há outros dois que atuam na área de turismo, porém apenas com curso de graduação, limitando assim ao único curso técnico da área ofertado.

A atuação na área de Turismo, Hospitalidade e Lazer acontece neste campus, desde 2002, com a criação do Curso Técnico em Turismo e Entretenimento, com uma formação mais ampla, a qual englobava o ensino nas áreas de agenciamento de viagens, eventos, hotelaria e lazer.

De acordo com as mudanças na legislação quanto a formação do guia de turismo que passou a exigir a formação por meio de curso técnico de nível médio e com a implantação do Catálogo Nacional dos Cursos Técnicos do Ministério da Educação (MEC) que desmembrou a área de Turismo, Hospitalidade e Lazer, nos seguintes cursos técnicos em: agenciamento de viagem; cozinha; eventos; guia de turismo; hospedagem; lazer e restaurante e bar, a instituição optou por reformular o curso anterior e fazer a devida adequação.

Em 2014, foi implantado no campus Maracanã o curso técnico em guia de turismo regional, com especialização em atrativos culturais e naturais, na modalidade médio técnico integrado, cujo conteúdo programático engloba as visitas técnicas, cujo PPC foi revisto em 2016.

\subsection{Manual para Viagem e Visita Técnica}


Em caráter exploratório e bibliográfico esta pesquisa foi desenvolvida com o objetivo de levantar dados e informações, por meio de documentação oficial que regulamenta a educação tecnológica e a profissão do Guia de Turismo, por meio de Projetos Pedagógicos de Cursos; matrizes curriculares, ementas e outras normatizações que permitiram justificar a importância e ainda por meio de um reduzido número de obras e inúmeros artigos, caracterizar as visitas e as viagens técnicas como metodologias de ensino-aprendizagem passíveis de serem aplicadas em cursos e níveis de ensino distintos.

A partir da identificação destes dados e do diálogo estabelecido com os docentes entrevistados que já realizaram ou que hoje realizam estas atividades nas áreas em que lecionam, permitiu uma melhor descrição do cenário educacional onde as mesmas são aplicadas. A entrevista em linhas gerais tinha como estratégia principal identificar se as referidas atividades são ou não adotadas pelos docentes, sua importância no desenvolvimento dos conteúdos e competências acadêmicas e a percepção dos mesmos com relação à organização e realização destas atividades. Se as etapas que permeiam a organização e a realização já estão definidas e sistematizadas pela Instituição de Ensino e em caso negativo, quais seriam as lacunas ou falhas que estes identificaram. O roteiro desta entrevista encontra-se no apêndice.

Com foco na melhoria da qualidade da prestação de serviço educacional, em especial, por meio da utilização das diferentes ferramentas que a educação coloca à disposição como as metodologias ativas de aprendizagem, aqui apresentadas como as visitas e viagens técnicas dentre inúmeras outras facilitadoras da absorção do conhecimento.

Por meio da consulta aos docentes foi possível identificar que em sua maioria consideram este tipo de metodologia como boa estratégia de aprendizagem, mas que não é realizada com tanta frequência devido a alguns impasses, como: se não for obrigatória, na maioria das vezes há baixa adesão dificuldade operacional para a preparação, organização e realização da atividade, não há documento que auxilie ou norteie essa organização.

Baseado no gerenciamento dos processos e sistemas e das práticas e metodologias aplicadas na produção de produtos e serviços é possível se perceber a qualidade. Com o objetivo de garantir a qualidade faz-se necessário equipar e preparar as instituições para que possam atender as diferentes necessidades de diferentes públicos. E em se 
tratando do setor educacional é preciso estar atento às demandas dos estudantes, pais, mercado e a sociedade onde estão inseridos (TODORUT, 2013).

O material consultado na busca de soluções ou otimização das lacunas existentes na organização e na realização das visitas e viagens técnicas corroboraram para a percepção de que a bibliografia permanece com foco na fundamentação pedagógica e a importância da prática destas atividades, deixando em segunda instância todo o processo de concepção e execução das mesmas. Esquecendo com isso o impacto negativo que uma má gestão neste sentido poderia causar em um aluno, em um curso e até mesmo na instituição que a operacionaliza.

A busca por atender as necessidades específicas de um mercado cada vez mais exigente, faz com que o turismo se reinvente com frequência e assim se segmente cada vez mais, seja por meio da formatação de novos produtos e serviços ou apenas pela adaptação daqueles pré-existentes (KUSHANO; ÁVILA; AMARAL SILVA, 2008).

Essa reinvenção do turismo vem permitindo a inserção das metodologias ativas de aprendizagem no contexto acadêmico de cursos e disciplinas que ainda não as detém inseridas oficialmente em seus PPCs, por meio da prática do turismo pedagógico.

O turismo pedagógico materializado por meio das visitas e viagens técnicas confere a ilustração dos conteúdos programáticos sob a ótica de uma metodologia de ensino aprendizagem cada vez mais ativa, a qual exige ir a campo, experimentar, vivenciar, questionar e muitas vezes ressignificar. Este segmento do turismo tem sua origem no estudo do meio, através de programas especialmente elaborados de acordo com os processos pedagógicos (PIRES, 2002).

Estas atividades são interativas, permitem o aluno se ver como ator, rompe com a rotina do espaço acadêmico tradicional, estimula uma consciência crítica, ao fugir do lugar comum, interliga a teoria e a prática e transpassam todas as áreas do conhecimento, permitindo aos cursos dos diversos segmento e níveis implantá-las.

Em se tratando de melhoria da qualidade na prestação do serviço educacional vislumbrada como uma das lacunas institucionais nesta pesquisa é preciso ressaltar que a qualidade precisa refletir a missão e a filosofia da gestão. Isso posto, torna-se fundamental uma análise sobre o planejamento, as práticas adotadas, o desenvolvimento, o retorno desta execução e seu alinhamento com os objetivos previamente delineados.

A qualidade precisa ser entendida como o reflexo de um conjunto de estratégias, com foco na organização das atividades, na formulação e execução das ações e ainda na percepção da demanda. 
Em deferência a pesquisa realizada cuja lacuna foi identificada na realização da visitas e viagens técnicas nos diversos níveis da Instituição, torna-se imprescindível a gestão da qualidade destas atividades, com vistas a analisar juntamente com os docentes ou outros solicitantes a importância e os objetivos pretendidos com estas atividades, o que e como será visitado, delinear o passo-a-passo do planejamento à execução e a implantação e que haja um controle etapa a etapa a fim de atender os objetivos almejados e corrigir possíveis falhas que possam prejudicar o bom andamento de cada processo.

Relacionados a percepções, experiências, ao fato de não poderem ser estocados, serem consumidos no ato de sua produção e o resultado depender da participação e do atendimento das necessidades da demanda, os serviços requerem um desempenho mais minucioso por parte da equipe que os organiza e operacionaliza. Evidenciando assim que a realização das visitas e viagens técnicas requerem um olhar e uma atuação cada vez mais direcionada à cultura da qualidade.

A obtenção e manutenção da qualidade não é um processo fácil, requer ações estratégicas direcionadas a minimizar e corrigir possíveis falhas, além de tornar o processo mais ágil e eficaz.

No curso de guia de turismo regional eleito como parâmetro para esta pesquisa e também nos demais, há lacunas que precisam ser sanadas, evidenciadas inclusive pela falta de padronização na organização das visitas e viagens técnicas, cuja organização e operacionalização dependem e variam de acordo com cada professor.

A compreensão e análise das metodologias de ensino aprendizagem aqui apresentadas direcionaram esta pesquisa, por meio da utilização do método da Design Science Research, a elaboração de um manual com o objetivo de orientar as partes envolvidas nestes processos. Por envolver, em sua maioria, integrantes de departamentos distintos nesta operacionalização vislumbrou-se a necessidade premente de um artefato que delineasse cada etapa deste processo.

A criação de um manual não tem como objetivo burocratizar ou engessar o funcionamento dos departamentos envolvidos, e sim prover cada departamento e seus atores de informações sobre todos os trâmites e etapas que norteiam a realização destas atividades, estabelecer padrões corretos para o serviço prestado, garantir o bom funcionamento do início ao fim e a qualidade por meio da supervisão e controle destas ações.

Foram identificadas lacunas de cunho organizacional, financeiro e operacional 
como as que mais interferem e inibem a prática destas atividades entre os docentes e como proposta o manual permite tratam item a item em sua materialização e ainda uniformizar as ações, para que sejam seguidas por todos os atores da instituição envolvidos ou que queiram se habilitar a realiza-las.

A elaboração do documento físico permite a consulta a qualquer momento, traz a padronização fundamental para um contexto de gestão da qualidade, pois elimina os ruídos de comunicação que muitas vezes levam as execuções de um mesmo serviço de diferentes formas na mesma instituição.

Questionamentos apontados nesta pesquisa relacionados à contratação de serviços e demais financiamentos necessitam de um rigor maior, pois estão precisam atender a legislação vigente e são auditados pelas instâncias superiores e órgãos externos de controle, fator que fundamenta e justifica a necessidade real de se ter um manual como documento norteador para a organização e execução das visitas e viagens técnicas na instituição.

A opção pela elaboração e a implantação de um manual tem origem na gestão de processos que visa convergir as ações de diferentes atores para um determinado propósito e atingir a excelência no resultado.

Com base na definição das necessidades, medição e análise da situação e dos serviços relacionados, das possibilidades de melhorias sugestionadas e do controle de todo este empenho, foi possível identificar o manual como o artefato que permite delinear e direcionar as ações necessárias na eliminação das lacunas e gargalos.

O manual, em seu sentido físico, contribuirá no sentido de ficar disponível para consulta e uso, facilitará a implantação ou o aprimoramento de uma cultura organizacional com uma metodologia padronizada, por meio da representação dos fluxos necessários, capaz de contribuir positivamente para a redução dos ruídos de comunicação, fatores estes que na maioria das vezes dificultam a sistematização e integração dos processos, setores e atividades. E ainda com a vantagem de permitir mudanças, após a fase de implantação. Contudo deverá ser mantido atualizado, de acordo com a legislação vigente e as normas que regem todas as atividades e serviços envolvidos. $E$ de acordo ainda, com as especificidades de cada curso.

O uso de um manual permite entender melhorar as demandas de cada setor e/ou instituição, selecionar os processos mais adequados a cada uma delas, elencar e priorizar as ações mais efetivas e documentar as atividades.

Para Max Weber, pai da Teoria da Burocracia, a formalização e o registro por 
escrito de rotinas e procedimentos devem estar de acordo com leis, normas e outras regras da instituição. A burocracia precisa ser entendida como um meio de organização de forma racional e eficiente, e não de forma pejorativa ou impeditiva de celeridade ao andamento dos processos. Devendo contemplar as seguintes características: caráter legal de normas e procedimentos, caráter formal das comunicações, caráter racional e divisão do trabalho, impessoalidade nas relações, hierarquia de autoridade, competência técnica e completa previsibilidade de funcionamento (WEBER apud CHIAVENATO, 2014).

O manual é um instrumento de apoio no qual se encontra a sistematização do passo a passo para a execução de atividades administrativas (GÓMEZ, 2001).

Deve conter ainda informações e descrições devidamente detalhadas e ordenadas de forma sistemática, instruções, funções, responsabilidades, procedimentos e políticas internas da instituição (PALMA, 2009).

Em caráter sistêmico e integrado o manual deve minimamente contemplar as recomendações relacionadas a cada uma das seguintes fases: concepção, pré-visita, visita e pós-visita.

\subsection{Aspectos relacionados ao Planejamento}

Nesta fase inicial, dedicada a concepção, é importante observar que estas atividades compreendem as visitas a atrativos e locais de interesses turísticos, eventos, empresas, organizações, instituições públicas ou privadas, ambientes de educação formal ou não formal, com perfil e relevância ao conteúdo proposto pelas disciplinas dos cursos ou pelas atividades de pesquisa e extensão. As saídas de estudo, atividades de campo e as viagens intermunicipais e interestaduais, com ou sem pernoite, também integram este perfil de atividade.

Estas atividades poderão ocorrer sob o caráter complementar, opcional ou obrigatório a depender da proposta do projeto pedagógico de cada curso aos quais se aplicam. Podendo ocorrer em parceria entre diferentes disciplinas, enfatizando a interdisciplinaridade e ampliando a área de conhecimento.

A participação nestas atividades está condicionada ao discente estar regularmente matriculado na instituição.

Os objetivos para a realização destas atividades precisam estar alinhados às metodologias de aprendizagem, ao enquadramento teórico-prático, à possibilidade do desenvolvimento do pensamento e senso crítico fora do ambiente comum da sala de 
aula, expandindo o conhecimento e a observação para os universos externos do ensino tradicional.

É importante também definir o tipo de cada visita, se é dirigida - na qual o professor é o responsável por tudo da condução do grupo à transmissão das informações, se semi dirigida - quando, além do professor, há a participação de terceiros como guias, monitores ou condutores ou a não dirigida: totalmente centrada nos alunos que conduzem, controla e transmites as informações.

As visitas/viagens técnicas podem ser propostas por docentes, técnicoadministrativo e discentes, sendo estes últimos desde que aprovados por um docenteorientador.

A responsabilidade pelo planejamento é de competência do organizador que cuidará de todos os documentos e trâmites necessários e obrigatórios.

A duração de cada atividade poderá variar de acordo com a programação, a disponibilidade dos locais receptores e da disponibilidade de recursos orçamentários. E também deverá estar em consonância com os objetivos, de modo a contemplar tão somente a programação e as atividades planejadas para o cumprimento do projeto. A carga horária destas atividades deverá ser cumprida durante o período letivo.

Nesta etapa dedicada à concepção das visitas/viagens deverá ser feita consulta à chefia imediata e/ou departamento financeiro a fim de ter conhecimento da dotação orçamentária anual, nas rubricas específicas para cada serviço, autorizada ao colegiado e dos prazos para abertura dos processos licitatórios e de contratação dos serviços necessários.

Em seguida estabelecer um programa semestral ou anual de visitas e viagens, já enquadrado no orçamento disponível.

Para somente a partir desta etapa solicitar autorização à chefia imediata e às diretorias pertinentes, apresentando o fluxo de visitas e viagens, a planilha de custos dos serviços (hospedagem, alimentação e seguro-viagem) e demais recursos, como bolsa-auxílio para os discentes, quando for o caso, para dar entrada nos processos para licitação e contratação. Esta etapa merece especial atenção em função de ter inúmeras particularidades por se tratar de contratação de serviços para órgão público. Existem prazos que precisam ser rigorosamente respeitados, trâmites obrigatórios e que quando não cumpridos ou mal executados podem comprometer ou dificultar o cumprimento do cronograma de visitas e até mesmo inviabilizar todo o planejamento anual.

É importante ressaltar que este controle acontece também em esferas externas 
à instituição, uma vez que a dotação orçamentária é oriunda do governo federal, tendo como supervisão e controle órgãos como o Ministério da Educação (MEC), Ministério do Planejamento Desenvolvimento e Gestão (MPOG) e o Tribunal de Contas da União (TCU). Portanto a utilização consciente e responsável do orçamento é o que permite a manutenção das atividades e a qualidade da prestação do serviço educacional.

\subsection{Aspectos relacionados à Organização e Formalização da Visita Técnica}

Etapa de concepção cumprida é preciso dar início a segunda, dedicada à organização, por meio inicialmente da formalização de todos os processos que podem envolver estas atividades, dentre eles a necessidade de verificar se os processos de recursos financeiros tramitados estão liberados e as devidas autorizações da chefia imediata para execução.

Dando continuidade à organização é necessária a elaboração do programa da visita/viagem técnica, elaboração de roteiros e itinerários, definição de objetivos, funções e atividades de cada participante, incluindo equipe técnica. Com a programação definida deve-se contatar os locais de visitação para agendamento e demais informações, na instituição de origem solicitar os auxílios de custo, o agendamento do transporte de acordo com a quantidade de passageiros e o roteiro a ser executado, autorização dos demais docentes quando tratar-se de atividade em período integral e que haja conflito de horário.

Ainda durante esta segunda etapa é obrigatório a recolha de documentos e realização dos registros pertinente, tais como: ofícios, memorandos, e-mails, cópia dos documentos dos participantes, autorizações dos responsáveis para os alunos menores de idade, termos de compromisso dos alunos maiores de 18 (dezoito) anos, termo de responsabilidade para atividades de aventura, quando houver.

\subsection{Aspectos relacionados à Execução da Visita Técnica}

Para esta terceira etapa destinada a realização da visita/viagem técnica é de fundamental importância, a elaboração da pasta do guia ou de visita, a qual deve conter toda a documentação que deverá ser apresentada ao longo da visita, para ingresso nos espaços, ordens de serviços de alimentação, hospedagem, lista de contatos, ficha dos passageiros, rooming-list, entre outros. 
Ainda nesta etapa deve-se dar especial atenção à transmissão dos informes sobre as normas referentes aos cancelamentos, substituições docentes, questões comportamentais e possíveis desligamentos, condições de visitação, horários, faltas, atrasos, embarques e desembarques, uso dos equipamentos disponibilizados, das proibições relativas às participações em determinadas atividades, uso de substâncias ilegais, alterações da programação sem prévia autorização, entre outras.

\subsection{Aspectos relacionados ao Encerramento e Prestação de Contas da Visita Técnica}

Esta quarta e última etapa deve compreender o pós-visita, momento destinado ao registro das atividades, desenvolvidas ou não, por meio relatórios, entrega de comprovantes para fins de prestação de contas, envio de documentos de certificação aos participantes, quando houver e de agradecimentos às instituições anfitriãs deste programa de visita/viagem técnica.

Capítulo à parte, os recursos financeiros merecem especial atenção, tendo em vista que este é um dos elementos mais citados como fator de dificuldade e insatisfação no que concerne à opção, por parte dos docentes, para implementação de visitas/ viagens técnicas.

As visitas e viagens técnicas para serem financiadas pela Instituição precisam estar previstas em documentos norteadores das políticas pedagógicas adotadas em cada disciplina e/ou curso enquanto atividades de ensino-aprendizagem.

Cada uma destas atividades, de acordo com suas especificidades demandaram serviços e organizações distintas, porém itens comuns a todos, tais como: diárias e passagens para docentes já se encontram previstos e são concedidos por meio de um sistema oficial do governo federal, o SCDP - Sistema de Diárias e Passagens.

Demais serviços precisam seguir a legislação em vigor, cujas contratações podem ocorrer por meio de registro de preço, realização de licitação, convênios, parcerias, entre outros conforme determinação do departamento responsável.

O custeio destes serviços é extensível aos discentes, incluindo transporte, hospedagem, entre outros respeitada as exigências e normas internas, os processos adequados para o custeio e acima de tudo o orçamento disponível.

Fator que muitas vezes dificulta a efetivação ou o bom andamento do processo para estas realizações é a falta de planejamento prévio ou o não cumprimento dos prazos. Por se tratar de trâmites em Instituição pública, a etapa do planejamento é um 
dos fatores fundamentais, tendo em vista que na maioria dos casos e principalmente dependendo do montante necessário para custear determinadas ações, faz-se necessário que esta ação tenha sido planejada ainda no ano anterior.

Antes do término do exercício fiscal de cada ano há que ser feito o planejamento orçamentário de todos os setores, especificando necessidades e aplicabilidade devidamente justificadas, as quais após a devida aprovação da autoridade competente interna serão encaminhadas aos órgãos de controle externos para a devida avaliação, aprovação e dotação orçamentária da Instituição para o próximo ano de exercício.

Desta forma torna-se primordial a atenção aos prazos e exigências da instituição neste sentido, porque a não previsão e solicitação de recursos poderá impactar no impedimento da realização das atividades planejadas.

\section{CONSIDERAÇÕES FINAIS}

Este artigo procurou apresentar a criação de um artefato, aqui representado por um manual, que permita normatizar os processos relacionados à organização e realização de visitas e viagens técnicas, em especial aplicadas ao curso médio técnico integrado em guia de turismo. Neste sentido, foram apresentados histórico, conceitos e aplicabilidade das atividades neste contexto.

O diálogo estabelecido com docentes que adotam este tipo de metodologia de aprendizagem contribuiu para uma melhor compreensão da importância, bem como da complexidade que envolvem estas atividades, sua efetiva realização e resultados almejados. As lacunas e dificuldades sinalizadas nas entrevistas evidenciaram a ausência de procedimentos organizados e ainda de mecanismos de acompanhamento e controle.

As visitas e viagens técnicas como mote para o aperfeiçoamento do serviço educacional ofertado pela instituição no curso de guia de turismo tem sua relevância ampliada quando da análise de sua importância enquanto metodologia ativa de aprendizagem, preconizada nos instrumentos norteadores do ensino, por sua especial contribuição ao conhecimento para a formação profissional e suas implicações no mercado de trabalho, geradas pelo binômio teoria e prática profissional.

Diante destes questionamentos este trabalho fundamentou-se nos paradigmas da Design Science por meio da exposição do ambiente interno, com objetivo de contribuir para o desenvolvimento de mecanismos metodológicos que permitam novas possibilidades de gestão de operações e administrativas, diferente da tradicionalmente 
utilizada.

A produção de um manual, como artefato não anula outras possibilidades de contribuições a serem exploradas, apenas evidencia que em um primeiro momento é necessário aperfeiçoar o modelo de gestão de processos com base na busca e na reorganização de soluções e tecnologias aplicáveis de forma sistêmica. E que contribua positivamente à uma melhor relação custo-benefício, desde a produção de documentos ao investimento empregado nestas ações.

Este trabalho foi desenvolvido no âmbito interno da Instituição em caráter documental, bibliográfico, aliado às entrevistas com o objetivo de aperfeiçoar a metodologia, aprimorar a teoria além de apresentar possível solução aos problemas mais prementes que permitam criar situações e condições ideais, contudo a avaliação do design não pode ser tratada, merecendo pesquisa futura.

A avaliação do design permite demonstrar por meio de métodos avaliativos a utilidade e a eficácia do artefato produzido. Porém, a regulamentação interna da Instituição determina que a implantação ou utilização de documentos que regulamentem os processos, como um manual, requer a apreciação e aprovação nos conselhos institucionais, hierarquicamente distintos, não sendo possível a validação em caráter experimental para este estudo.

Contudo este trabalho ressalta a necessidade de apresentar possibilidades da melhoria da qualidade das atividades ofertadas, bem como dos trâmites desenvolvidos pelos docentes e demais atores envolvidos no processo, como forma de sanar a lacuna institucional por meio de um conjunto de estratégias com foco na organização, na formulação e execução das ações e ainda na percepção da demanda, os alunos.

\section{REFERÊNCIAS}

CAMPOS, F. H.; SERPA, E. M. Guia de turismo: viagens técnicas e avaliação. São Paulo: Érica, 2014.

CHIAVENATO, I. Introdução à Teoria da Administração. 9ạ. ed. Barueri: Manole, 2014.

CHIMENTI, S.; TAVARES, A. D. M. Guia de turismo: o profissional e a profissão. 5ạ. ed. São Paulo: Senac São Paulo, 2016. 
DRESCH, A. Design Science e Design Science Research como artefatos metodológicos para engenharia de produção. Universidade do Vale do Rio dos Sinos. São Leopoldo, p. 184. 2013.

DRESCH, A.; LACERDA, D. P.; ANTUNES JÚNIOR, J. A. V. Design Science Research: Método de pesquisa para avanço da ciência e tecnologia. 1. ed. Porto Alegre: Bookman, 2015.

FARIA, A. R. C. Visitas de estudo: Um desafio pedagógico no ensino da história. Dissertação Instituto Poltécnico de Viana do Castelo. Viana do Castelo, p. 140. 2014.

GÓMEZ, Á. I. P. A cultura escolar na sociedade neoliberal. Porto Alegre: Artmed, 2001.

IFSP. Portaria no 2095, art 10. Instituto Federal de Educação, Ciência e Tecnologia de São Paulo. São Paulo. 2011.

KUSHANO, Elizabete Sayuri. Turismo Pedagógico na Região do Contestado no Estado de Santa Catarina: aprendizados sobre território e poder para as crianças. In: FRAGA, N.C. (org.). Guerra do Contestado: o massacre insepulto do Brasil. Florianópolis: Editora Insular, 2012.

ÁVILA, Marco Aurélio; AMARAL SILVA, Tatiana I. Segmentação de mercado: uma abordagem sobre o turismo em diferentes faixas etárias. Caderno Virtual de Turismo, vol.8, núm.2. Rio de Janeiro: Universidade Federal do Rio de Janeiro, 2008.

MEC. Catálogo Nacional de Cursos Técnicos. Brasília: [s.n.], 2016.

. Concepção e diretrizes. Ministério da Educação. Brasília. 2008.

MONTES, V. A. Saberes profissionais do guia de turismo: passeios turísticos em perspectiva etnográfica. Universidade Federal da Bahia. Salvador, p. 272. 2013.

NETO, L. M.; ANDRADE, R. O. A gestão privada do turismo. In: TRIGO, L. G. G. Turismo: como aprender, como ensinar. São Paulo: Senac, 2001. p. 135-151. 
PALMA, J. Manual de procedimiento. Villa Álvarez: [s.n.], 2009.

PIRES, Paulo dos Santos. Dimensões do Ecoturismo. 2a ed. São Paulo: Ed. SENAC, 2002.

REBELO, B. J. R. R. L. D. A. Visitas de estudo: Uma estratégia de aprendizagem.

Dissertação - Universidade Lusófona de Humanidades e Tecnologias. Lisboa, p. 67. 2014.

TODORUT, A. V. The need of total quality management in higher education. Procedia Social and Behavioral Science, Târgu Jiu, v. 83, p. 1105-1100, 2013.

TRIBE, J. Tribes, territories and networks in the tourism academy. Annals of tourism, $v$. 37, n. 1, p. 7-33, 2010.

VELOSO, M. P. Visita técnica: disciplina curricular para os cursos de turismo.

Universidade de Brasília. Brasília, p. 139. 2003. 